\title{
Importance of Effective Communication in Public Organisations
}

\author{
Osabiya Babatunde (Lecturer/ Programme Coordinator) \\ Public Administration, School of Management Sciences, National Open University of Nigeria \\ 14/16 Ahmadu Bello Way, Victoria-Island, Lagos, Nigeria
}

Tel: 234-8033-869-291Ｅ-mail: osabiyababatunde@yahoo.com

Received: April 16, 2015 Accepted: July 27, 2015 Published: November 20, 2015

doi:10.5296/iss.v3i2.8596

URL: http://dx.doi.org/10.5296/iss.v3i2.8596

\begin{abstract}
Communication has crucial impacts within or among workgroups in both private and public organizations. Communication can be a channel to flow information, resources, and even policies. Given the importance of organization communication and its managerial impacts, further research is needed to explore this topic as it relates to both private and public administration field. To this end, this study assesses the impacts of organizational communication on the perception of red tape by comparing internal communication with external, especially client-oriented, communication in both public and non-profit organizations.

Utilizing current literature, this paper will examine effective organizational communication within a private and public organization. Many organizations today often look at communication and leadership as one-dimensional; the inability of leaders in small organizations to adapt to a leadership style that effectively communicates with the employee hinders organizational performance. This study examines the communication exchange within a private and public organization and its effects on the organizational culture and employee performance.

This study summarizes the increasing importance of organizational communication, the basic theoretical perspectives that guide the study of communication and the key distinctions that guide the study of organizational communication, the key functions of communication in organizations. Because organizational communication has become such a big topic, this study is limited to addressing internal and external organizational communication.
\end{abstract}

Keywords: organizational communication, theories of communication, types of communication, barriers of communication, communication as constitutive of organizations 


\section{Macrothink}

Issues in Social Science

ISSN 2329-521X

2015, Vol. 3, No. 2

\section{Introduction}

Communication is probably one of the most frequently cited sources of interpersonal conflict when it is poorly carried out. It is equally an important lifeline in every organization. Many of the problems that occur in organizations are the direct result of people failing to communicate. What we hear or understand when someone speaks to us is largely based on our experience and background. Instead of hearing what people have told us, we hear what our minds tell us, they have said we have preconceptions about what people are going to say, and if what they say does not fit into our framework of reference, we adjust it until it does (Armstrong, 2008: 17). Lack of effective communication is a serious problem within an organization, and this can lead to confusion and can cause a good plan to fail.

When we experience problems in the organization, most times, their causes are usually identified to poor communication. This is also because communication is the source of information used by managers in making decisions that affect the organization. Managers depend on their Communication Skills to get the information required to make decisions and to transmit the results and intention of the decisions to other people. Research has shown that Managers used as much as $80 \%$ of their time in verbal interaction with other people i.e. Manager spends time:

(i) giving and receiving directives

(ii) participating in Conferences

(iii) receiving telephone calls

(iv) instructing subordinates

(v) heating grievances, discipline and counseling staff

(vi) reading memos, letters, reports, etc.

(vii) writing a wide variety of messages etc

Therefore any organization which fails to communicate properly must be prepared to face the consequences. Any idea no matter how great is useless until it is transmitted and understood by others. Perfect Communication would exist 'when a thought or idea is transmitted so that the mental picture perceived by the receiver was exactly the same as that envisioned by the sender.

Against the foregoing backdrop, this paper will attempt to discuss the following:

Conceptual Clarifications/Definition

1) Functions of Communication

2) Communication Process

3) Communication Patterns

4) Barriers to Communication; and

5) Effective Communication 


\section{Conceptual Clarifications}

Research has shown that there is no single definition that covers the wide range of behaviours studied in all areas where communication occurs, as such there is no single definition upon which scholars in this field agree (Williams, 1978: 86) Nonetheless, communication is usually described along a few major dimensions as stated in (Wikipedia, 2007 48)

(i) Content (what types of things are communicated)

(ii) Source (Emisor/Sender/Encoder (by whom)

(iii) Form (in which form)

(iv) Channel (through which medium)

(v) Destina ${ }^{t_{i o n}} /$ Receiver/Target/Decoder (to whom)

(vi) Purpose/Pragmatic aspect (with what kind of result)

Various definitions have been suggested for communication, while some may be convincing, some may also be narrow depending on from which perspective, we are looking at. Randall (1984: 156) sees communication as the meaningful transfer of information from one person (or group) to another. In this regard, communication does not occur unless one person transmits a piece of information to another person, who receives the piece of information and the received information has meaning to the receiver.

All these three conditions must be met for communication to have occurred. Similarly, Cushway and Lodge (1999: 189) believe communication can be regarded as effective when the ideas and intentions of one person are successfully conveyed to another.

It is further argued by Obisi (2003:218-219) that Communication is generally understood as spoken or written words. But in reality, it is more than that. It is the sum total directly or indirectly, unconsciously or conscio usly transmitted words, attitudes, feelings, actions, gestures and tones. Even silence is an effective way of communication. A twist in the face is often more expressive disapproval than hundreds of words put together. Tone, very often than not, destroys the meaning of the words uttered, that is, A Casual Leave granted with sarcastic slang in the tone, pinches more than the denial of the leave with reasons well explained.

Communication is also viewed as a process that allows organisms to exchange information by several methods. It requires that, all parties understand a common language that is exchanged with each other, Exchange requires feedback. The word Communication is also used in a different context where little or no feedback $\bullet$ is expected such as broadcasting or where the feedback may be delayed depending on the methods, timing, technologies and means for feedback (Wikipedia, 2007).

Having examined few definitions of Communications out of several others, this paper will adopt Robbins (1989: 267) simple definition which views Communication as the "transference and understanding of meaning. This clearly indicates that mere transmitting of information do not translate to Communication. Such information therefore must be 
understood. Therefore Communication must include both the transference and understanding of meaning.

\section{Methodology}

This study employ qualitative method of analysis and the sources of data are gathered through textbooks, journals, and documents and this secondary data are analyzed through content analysis.

\section{Theories of Communication}

Three major theories of communication can be identified:

1. The information theory

2. The interpersonal theory; and

3. The organizational theory

\section{The Information Theory}

This is oriented with the theory of mathematics and is concerned with the transmission aspects of the communication process. Specifically, the transmission consists of encoder (sender) and decoder (receiver) in terms of both their functional roles and their contribution to the achievement of a given objectives.

\section{The Interpersonal Theory}

This is the opposite of the information theory. The interpersonal communication approach is behaviourally oriented. The major focus is on transferring information from one person to another. Communication is looked upon as a basic method of affecting behavioural change and it incorporates the psychological process (perception, learning and motivation) on the one hand, and language on the other. Listening sensitivity and non- verbal communication (body language) are closely associated with this approach. There must be both a sender and a receiver in order for interpersonal communication to take place. The sender is obviously important to communication; but so is the neglected receiver who gives feedback to the sender. The feedback must be effective to the receipts with specific information, so that they know what must be done to correct the situation.

\section{The Organizational Theory}

This represents the midpoint between the information theory and the interpersonal approach. Traditionally, the organizational structure was viewed as a network over which there were linear information flows. This step-by-step information approach was counted with the dynamic and interactive in the downward and upward (vertical) system and interactive (horizontal) systems (Eneanya, 2009).

\section{Functions of Communication}

Communication has four major functions within the organization. Robbins (267:1989]. These include:

1) Information: Communication facilitates decision making. It provides information that individuals and groups need to make decisions through the provision of data to identify and evaluate alternative choices. 


\section{Macrothink Institute ${ }^{\mathrm{TM}}$}

2) Motivation: Communication fosters motivation by clarifying to employees what is to be done, how it will be done and what can be done. Communications and praises to employees also motivate and encourage commitment to organizational objectives.

3) Control: Communication acts to control member behaviour in various ways. Every organization has authority, hierarchies, Guidelines and Regulations that employees are required to follow For instance, employees know how to communicate their grievances, know which procedures to use to enjoy certain amenities or privileges and structures laid on how to process various requests.

4) Emotional Expression: Emotive uses of Communication allow for the expression of feelings and the satisfaction of social needs. Employees within their work groups Communicate among themselves to show their frustration or feelings of satisfaction which ultimately provides a release for their emotional expressions of feelings.

\section{Communication Process}

Communication between one person or groups can be thought of as a process or flow that occur in a variety of ways (face to face, written, gesture, phone etc). All have in common the communication process which starts with a source, who is responsible for selection of an intended message (message you intend to transmit) and encoding (convent the idea of the message into some transmittable form either kitten, by word, gesture etc). The encoded message is passed through medium (channel) which serves as the physical medium for the transmission of the message. The receiver then retranslates (decodes) the message from the sender to give it meaning (by reading, listening, seeing, feeling etc). Once the message is decoded, it is accepted as received. The result is the transference of meaning from one person to another (Robbins, 1999: 268) (Figure 1).

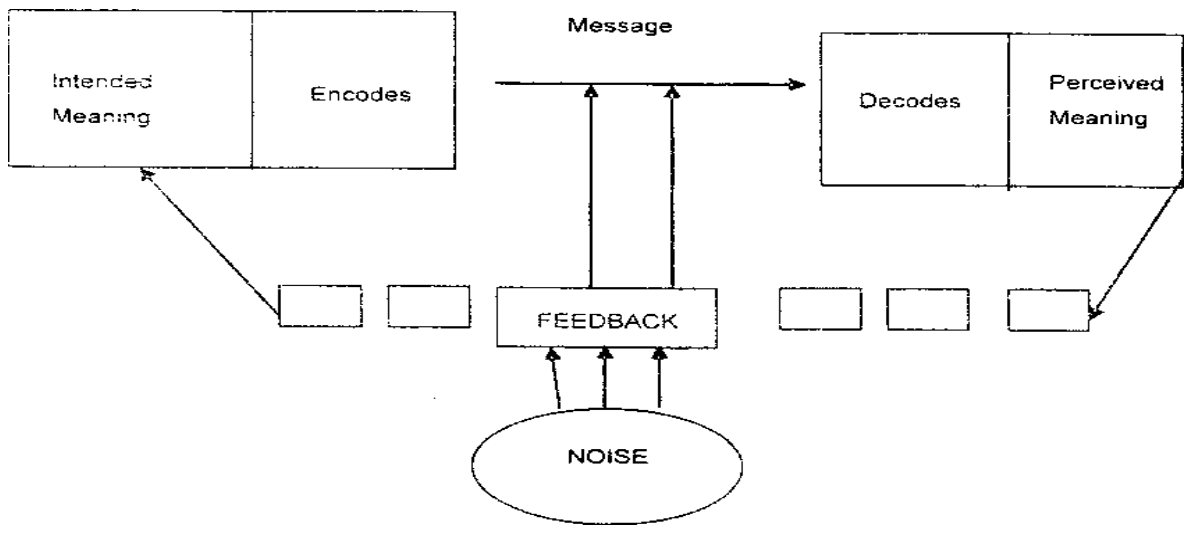

\section{Communication in the Public Service}

Much of government business is conducted through various Communication processes which may be through meetings, telephone conversations and other forms of electronic communication or face to face. The most important method of conducting Government business however is through various forms of written communication. Therefore 


\section{Macrothink}

Communication in the public service is carried out through a variety of channels.

These include the following amongst others:

1) Minuting in file.

2) Letters

3) Minutes of meetings

4) Memoranda/Memos

5) Telegram

6) Reports

7) Circulars

8) Posters and Bulletins

9) Periodicals etc.

\section{Communication Pattem}

Communication patterns encompasse the directions that communication takes in groups and in organization as well as the channels by which communications flow. Communication can flow vertically and laterally. The vertical dimension can be further divided into downward and upward direction.

\subsection{Downward}

This is the communication that flows from one level of a group or organisation to a lower level. This involves the dissemination of information from highest hierarchy downwards. This could be from the top management down to other levels. It is used by group or organization managers to assign goals, provide job instructions, explain policy direction and procedures, point cut problems that need attention and offer feedback about performance.etc (See diagram below).

\begin{tabular}{|ll|}
\hline Organization & Top Management \\
& Middle Management \\
& Employees \\
\hline
\end{tabular}

\subsection{Upward}

This is communication that flows to a higher level in a group or organization. It is used to provide feedback to top management, inform them about progress toward goals. This methods also keep managers aware of how employee feel about their jobs. Examples of 
upward Communication include performance reports prepared by middle management for top management, suggestion boxes, grievance procedures, etc. (See diagram below).

$\begin{array}{ll}\text { Organization } & \text { Top Management } \\ & \text { Middle Management } \\ & \text { Employees }\end{array}$

\subsection{Lateral}

When Communication takes place amongst members of the same work group, or amongst managers of the same level or among any horizontally equivalent personnel, it is referred to as lateral Communication

\section{Types of Communication}

Communication can either be formal or informal.

\subsection{Formal Communication}

Communication is said to be formal, if the dissemination of information, messages and ideas are according to prescribed or fixed rules and customs. It is external rather than natural because it is notes a result of the intrinsic feelings of the actors but imposed on them by the organization (Obisi, 2008: 223). Such Communication is usually very rigid and follows definite pattern and it is official in nature. It may be oral or written, vertical or horizontal. They are usually bureaucratic in nature and the directives or instructions are to be carried out.

\subsection{Informal Communication}

This is described as any interaction or relationship which exists in any organization which is not deliberate, rigid, or structured. Such interaction and relationship are as a result of natural feelings without any outside interference, constraint or premeditation (Obisi, 2003: 224). It may also be viewed as messages conveyed through body movements, the intonations or emphasis we give to 'words, facial expressions and the physical distance between the sender and receiver (Robbins: 1989, 282).

\subsection{Barriers to Effective Communication}

In Communication, apart from the general distortions in the Communication process, there are other barriers to effective Communication. As noted by Cushway and Lodge $(1999,189)$. Barriers to Communication can come from a number of Sources. The problem may be with the sender of the message who may be unable or indeed unwilling to communicate the necessary message very clearly, or with the receiver who may be unable or unwilling to understand the message being sent, or there may be environmental factors affecting the conditions under which the message is conveyed, such as noise. Therefore, we could examine barriers to Communication from the four important levels of Communication i.e. 


\section{Macrothink}
a) Sender's levels
b) Transmission/Channels levels.
c) Receivers level; and
d) Feedback level.

\section{Sender's Level}

1) Poor Communication skills of the Sender; the sender of any particular message may not be particularly articulate either verbally or in writing, and will therefore fail to convey the information accurately.

2) Information underload: where information is too scanty for the receiver to give adequate feedback or take a decision, it becomes a barrier.

3) Information overload: Many messages get lost because of the sheer volume of information being passed to the receiver. When someone receives too many Internal Memoranda on relatively trivial issues, the important messages may get lost unless special attention is drawn to them in some way.

4) Dislike between Sender and Receiver: Sometimes, when there is dislike - between the two, their emotional state will affect the way that message is perceived. Either the Sender or the Receiver may not listen or pay attention or may not be very objective to what is said on that topic.

5) Failure to pitch the message at the receiver's language and experience level: There is no doubt that Communication itself is determined by our skills, knowledge and attitude and who we want to communicate with.

6) We can only communicate well, when we adjust our knowledge and skills to the level of the receiver. Otherwise Communication will not be effective.

\section{Transmission Level}

1) Physical Noise can easily distort communication flow.

2) Travelling through many links before reaching its destination. The more levels a message must go through to get to the bottom of the hierarchy, the more likely that a sizeable portion of the original information will be lost or substantially distorted.

3) Selection of a poor channel/Transmission may also cause distortion.

\section{Receiver's Level}

1) Failure to understand the message by the receiver is a serious barrier.

2) Where the receiver is threatened by the message.

3) Where the receiver displays impatience for any reasons when receiving the message.

4) Preoccupation: When the receiver of the message is pre-occupied with other matters, the content of the message being received may not be fully appreciated.

5) Where there is a negative attitude towards the receiver himself, the message and the sender, the communication may not likely be effective. 


\section{Mll Macrothink}

Issues in Social Science ISSN 2329-521X 2015, Vol. 3, No. 2

6) Physical conditions or environmental factors may also prevent the receiver from understanding.

7) Where the receiver does not understand certain "terms" used in the message, Communication becomes ineffective.

\section{Feedback Level}

1) Feedback not provided at all; and

2) Where feedback is delayed, it may also affect effective Communication.

\section{Seven Deadly Sins of Management Communications}

If you expect to be a successful Manager, you need to be aware of the seven deadly sins (Reprinted from Stephen Robbins (1999: 284). Committing any one of them will lessen your effectiveness.

1) Not realising that your message may get a different response than you expect. People see the world differently, based on their experiences, values, attitudes, and perceptions. Expect to be misunderstood and adjust your message anticipating ways your ideas could be misinterpreted.

2) Impressing instead of expressing. First and foremost, the objective of communication is to transfer information, not exert power. Too often managers are more concerned with sounding impressive and appearing knowledgeable than in making sure the ideas get across.

3) Choosing the wrong medium. It's easy to get in the habit of using the same medium over and over again. You have choices: telephone, memos, letters, interviews, group meetings, electronic mail, etc. Use the one that will most effectively carry the message you want

4) Failing to close the feedback loop. Effective communication requires understanding by the recipient. Use feedback to insure that the message received is the message sent.

5) Applying a nonverbal veto. Studies show that as much as 78 percent of meaning is transmitted nonverbally through tone of voice, appearance, timing, and the like. Consider how these nonverbal messages might distort your intended message.

6) Not helping your reader or listener get the message. Don't turn your communique into an Easter egg hunt. Clarify the more important points in your message. As the guide for public speaking reminds us, "Tell 'em what you're going to tell 'em; tell 'em, and then tell 'em what you told 'em."

7) Viewing communication as a fringe benefit. Communication is the essence of a manager's job. It is not a morale booster or "icing on the cake." Good communication practices is not just a desirable quality; it is a requirement for effective management.

\section{Recommendations for Effective Communication}

In view of the barriers to Communication identified and examined, what can individuals do to minimize the problems and attempt to overcome these barriers. The following 


\section{Macrothink

suggestions/recommendations may be helpful in making Communication more effective.

1) Be clear about the message you want to convey and the reasons for the message: for example to inform, to amuse, to seek information and so on.

2) Select the appropriate method of Communication, having regard to content, timescale and target audience.

3) Prepare the message in the appropriate format and language having particular regard to the nature and background of the people to be communicated with.

4) Where possible, use more than one means of Communication to reinforce the message and be prepared to repeat it if necessary

5) Try to ensure that the sender of the message is someone with credibility in the organization.

6) Consider, what is in it for those the message is for and highlight the benefits of any particular suggestion.

7) Give examples, where appropriate to support the message.

8) Try to give factual information and careful explanation where required.

9) Structure any argument logically working up to the conclusions.

10) Use any points you know people will agree with to reinforce your statements,

11) Try to ensure that the message is interesting.

12) Test out your proposed message and take account of any constructive feedback.

13) Know the purpose of Communication;

14) Adopt a Communication style.

15) Avoid Communication overload and underload.

16) Try to get and retain the receiver's attention.

17) Use language that is at the experience level of the receiver.

18) Listen empathetically.

19) Make intelligent use of informal Communication.

20) Update and refine your Communication Skills.

\section{Conclusion}

Greater attention should be paid to the communication as the element of organisational behaviour because of the growing changes within organisations which face the leadership with new challenges and opportunities for testing the different organizational be haviour concept modes. By identifying the level of communication satisfaction within the 
organisation we get an insight into organisational forces, but simultaneously also get an insight into weak points in the area of communication within the organisation. We can also use them as the basis for making important business decisions within the organisation.

We find it essential that there be a great investment from the side of the organisation towards satisfaction growth on those levels where there has been shown the least satisfaction. It is important to develop awareness about the importance of communication which is shown through individual growth, job satisfaction and motivation of the employees which again leads to employees' loyalty towards their parent organisation.

\section{References}

Armstrong, M. (2008). How to be in Even Better Manager (7th ed.). London, Kogan Page.

Barry, C., \& Derek, L. (1999). Organizational Behaviour and Design. London, Princewater House Coopers.

Berlo, D. K. (1960). The Process of Communication. New York, New York: Holt, Rinehart, \& Winston.

Cayer, N. J., \& Weschler, L. F. (1988). Public Administration: Social Change and Adaptive Management. New York, St. Martins Press.

Conrad, C., \& Poole, M. S. (2005). Strategic Organisational Communication in a Global Economy. Belmont C A Thompson Wadsworth.

Drenth P. J. D. H., \& Dewolff, C. J. (Eds.) (1998). Handbook of Work and Organizational Psychology (2nd ed.) East Sussex, Psychology Press Ltd.

Eneanya, A. N. (2009). Principles and Practice of Public Personnel Administration in Nigeria. Lagos, Concept Publications.

Eneanya, A. N. (2010). Public Administration in Nigeria; Principles, Techniques and Applications. Lagos, Concept Publications.

Luthas, F. (2005). Organisational Behaviour. McGraw-Hill.

Maduabum, C. P. (2003). Contemporary Issues on Public Policy Analysis in Nigeria. Lagos, ASCON Press.

Maduabum, C. P. (2008). The Mechanics of Public Administration in Nigeria. Lagos, Concept Publications.

Miller, K. (2009). Organizational Communication: Approaches and Processes (5th ed.). Boston, MA: Wadsworth Cengage Learning.

Munter, M. (2002). Guide to Managerial Communication (6th ed.). Englewood Cliffs, NJ; Prentice Hall.

Myers, M. T., \& Myers, G. E. (1982). Managing by Communication - An Organizational Approach. New York: McGraw-Hill Book Company. 


\section{Macrothink}

Issues in Social Science

ISSN 2329-521X 2015, Vol. 3, No. 2

Obisi, C. (2003). Organizational Behaviour: Concept and Application. Lagos, Malthouse Press Limited.

Onah, E. I. (2009). Theory and Practice of Administration. Lagos, Concept Publications.

Randcil, D. (1984). Organizational Behaviour. Illinois Richard Irwin Inc.

Rogers, E. M., \& Rekha, A. R. (1976). Communication in Organizations. New York: Free Press.

Scammell, B. (1990). Communication Skills. London, Macmillan Education Ltd.

Schermerborn, H., \& Osborn (1985). Managing Organizational Behaviour. New York, John Wiley and Sons.

Steprien, R. (1989). Organizational Behaviour: Concepts, Controversies and Applications (4th ed.). London, Prentice-Hall International

Weinstein, K. (1998). In D. M. Stewart (Ed.), Communication, In Handbook of Management Skills (3rd ed.). USA, Gower.

Williams, J. O. (1978). Human Behaviour in Organizations Cincinnati. South Western Publication Co. 